\title{
Impact of Sleep Dysfunction on Anorectal Motility in Healthy Humans
}

\author{
Tso-Tsai Liu, ${ }^{1}$ Chih-Hsun Yi, ${ }^{1}$ Chien-Lin Chen ${ }^{1 *}$ and William C Orr ${ }^{2}$ \\ ${ }^{1}$ Department of Medicine, Buddhist Tzu Chi General Hospital and Tzu Chi University, Hualien, Taiwan, ${ }^{2}$ Lynn Institute for Healthcare Research, \\ University of Oklahoma Health Sciences Center, Oklahoma City, OK, USA
}

\section{Background/Aims}

Sleep dysfunction is associated with altered gastrointestinal function and subsequently exacerbations of gastrointestinal problems. We aimed to investigate whether sleep dysfunction would influence anorectal motility as determined by anorectal manometry. The effect of anxiety on anorectal motility was also determined.

\section{Methods}

A total of 24 healthy volunteers underwent anorectal manometry. The anorectal parameters included resting and squeeze sphincter pressure, sensory thresholds in response to balloon distension, sphincter length, rectal compliance, and rectoanal inhibitory reflex. Sleep dysfunction was subjectively assessed by using Pittsburgh Sleep Quality Index (PSQI). Anxiety was assessed by the application of the State-Trait Anxiety Inventory questionnaire.

\section{Results}

There were sixteen subjects without sleep dysfunction (7 women; mean age, 22 years) and eight subjects with sleep dysfunction (2 women; mean age, 22 years). There was no group difference in the volume threshold for rectoanal inhibitory reflux, rectal compliance or sphincter length $(P=N S)$. Anal sphincter pressure did not differ between the groups $(P=N S)$. The rectal sensitivity for different levels of stimulation did not differ between the groups $(P=N S)$. Sleep quality as determined by PSQI correlated with rectal compliance $(r=0.66, P=0.007)$. Although there was no differences in any manometric parameters between subjects with and without anxiety, the anxiety score correlated with rectal compliance $(r=0.57, P=0.003)$.

\section{Conclusions}

Despite a positive association between rectal compliance and the level of subjective sleep or anxiety, sleep dysfunction did not apparently affect most of anorectal function in healthy subjects, nor did anxiety.

\section{(J Neurogastroenterol Motil 2011;17:180-184)}

\section{Key Words}

Anxiety; Manometry; Sleep

Received: December 7, 2010 Revised: January 21, 2011 Accepted: January 30, 2011

(c) This is an Open Access article distributed under the terms of the Creative Commons Attribution Non-Commercial License (http://creativecommons. org/licenses/by-nc/3.0) which permits unrestricted non-commercial use, distribution, and reproduction in any medium, provided the original work is properly cited.

*Correspondence: Chien-Lin Chen, MD

Department of Medicine, Buddhist Tzu Chi Hospital, 707, Sec. 3, Chung-Yang Rd., Hualien 970, Taiwan

Tel: +886-3-8561825, Fax: +886-3-8577161, E-mail: harry.clchen@msa.hinet net

Financial support: This study was supported by a grant of Buddhist Tzu-Chi General Hospital, Taiwan (TCRD-98-54).

Conflicts of interest: None. 


\section{Introduction}

Sleep deprivation is shown to heighten visceral perception and implicated as an etiological factor in chronic hyperalgesia syndromes. ${ }^{1}$ Previous data have suggested that a majority of patients with functional gastrointestinal (GI) disorders have sleep disturbance. ${ }^{2}$ Visceral hypersensitivity is also associated with poor sleep. ${ }^{3}$ Alterations in anorectal function during sleep were reported by Orkin et al, ${ }^{4}$ who noted that decreased anal resting pressure was associated with marked minute-to-minute variations in pressures during sleep in healthy controls.

However, it is shown that acute mental stress does not influence rectal sensitivity to balloon distension in healthy adults. ${ }^{5}$ Data are very few regarding the effect of sleep dysfunction on anorectal function. The aim of this study was to increase our understanding of sleep influencing anorectal physiology by investigating whether there was a difference in anorectal function as determined by anorectal manometry between healthy adults with and without sleep dysfunction. We also investigated whether anxiety had the effect on anorectal motility.

\section{Materials and Methods}

\section{Subjects}

This prospective study was approved by the Buddhist Tzu Chi General Hospital Institutional Review Board. All subjects were provided with written informed consent and interviewed about their general health and GI symptoms prior to the studies. A total of 24 healthy volunteers with no history of an underlying medical condition, alcoholism, psychological illness, medications affecting mentality or sleep, previous GI surgery or GI symptoms participated in this study. All subjects were enrolled from a university student population. Subjects with poor communication or impaired hearing were excluded. Prior to the study, all subjects were interviewed by telephone regarding their bowel habits and sleep quality. All subjects with normal bowel habits had the bowel movements between 3 times per week and 3 times per day. ${ }^{6}$ In particular, there was no evidence of an acute or chronic pain syndrome or abdominal symptoms, personal history or physical examination. Irritable bowel syndrome (IBS) was also excluded according to the ROME III criteria, ${ }^{6}$ which include recurrent abdominal pain or discomfort at least 3 days per month in the last 3 months associated with 2 or more of the following: (1) improve- ment with defecation, (2) onset associated with a change in frequency of stool and (3) onset associated with a change in form (appearance) of stool.

\section{Anorectal Manometry}

Patients were instructed to evacuate the rectum and received a Fleet's enema before the test. The probe was a $4.5 \mathrm{~mm}$ diameter, solid state catheter with multiple pressure transducers (Sandhill Scientific, Inc, Highlands Ranch, CO, USA) and a lumen for balloon inflation. A $5 \mathrm{~cm}$ balloon was tied to the distal end of the catheter. The lubricated catheter was introduced into the rectum as patients lay in the left lateral position with their hips and knees flexed to $90^{\circ}$. Average resting and squeeze pressures (maximum and sustained) were recorded by the stationary pull-through technique. The threshold volume for rectoanal inhibitory reflexes was assessed by distending the rectal balloon in progressive 10 $\mathrm{mL}$ decrements, starting at $60 \mathrm{~mL}$, until anal sphincter relaxation was observed at lower volume of distension. Rectal sensation was evaluated with rectal balloon inflated at an interval of $10 \mathrm{~mL}$ until the subject reported first sensation. The balloon volume was then increased by steps of $30 \mathrm{~mL}$ so that subjects experienced the sensations of urge to defecate as well as maximum distension. The threshold volumes for inducing these sensations were recorded. Rectal compliance for each balloon distention was derived from the slope of the volume-pressure curve.

\section{Subjective Sleep and Anxiety Assessment}

The Pittsburgh Sleep Quality Index (PSQI) score was used to determine sleep disturbance. The PSQI score is a standardized rating scale, which has been validated as differentiating from 'poor' to 'good' sleep. ${ }^{7}$ It evaluates sleep disturbances in seven dimensions: subjective sleep quality, sleep latency, sleep duration, habitual sleep efficiency, sleep disturbances, use of sleep medication and daytime dysfunction. Each dimension is rated on a 4-point scale (0 to 3 , with 3 indicating more profound effect), which is summed together to yield a global score. A global score $>5$ indicates "poor sleep." Levels of anxiety were assessed by the State-Trait Anxiety Inventory (STAI) questionnaire. ${ }^{8}$ The STAI state anxiety includes 20 items rated on a 4-point Likert-type scale from 1 (not at all) to 4 (very much). Normal adults without anxiety have the score less than $40 .^{9}$

\section{Statistical Methods}

Data were expressed as mean \pm SEM. The normality of all data was examined by D'Agostino's K-squared test. Statistical 
comparisons were assessed using student's $t$ test. Correlations were studied with the Pearson test. A $P$-value $<0.05$ was considered as statistically significant.

\section{Results}

A total of 24 healthy subjects ( 9 women; mean age, 22 [20-25] years) participated in this study. All subjects tolerated the procedures without any adverse effect. All subjects were thus stratified into 2 groups, ie, without sleep dysfunction and with sleep dysfunction. Both groups displayed similar demographic results regarding age, gender, weight, height and body mass in$\operatorname{dex}$ (Table 1).

The rectal sensitivity for different levels of stimulation did not differ between the groups $(P=\mathrm{NS}$ ). There was no difference between groups in the threshold volume for RAIR, rectal compliance, or anal sphincter length $(P=\mathrm{NS})$. Anal sphincter pres-

Table 1. Demographic Data in Subjects With and Without Sleep Dysfunction

\begin{tabular}{lcc}
\hline \multicolumn{1}{c}{ Variable } & $\mathrm{SD}(-)(\mathrm{n}=16)$ & $\mathrm{SD}(+)(\mathrm{n}=8)$ \\
\hline Age $(\mathrm{yr})$ & $22 \pm 0.4$ & $22 \pm 0.7$ \\
Gender $($ female $)$ & $7(43 \%)$ & $2(25 \%)$ \\
Height $(\mathrm{cm})$ & $165 \pm 2$ & $162 \pm 1$ \\
Weight $(\mathrm{kg})$ & $59.9 \pm 0.6$ & $60.7 \pm 0.7$ \\
BMI $\left(\mathrm{kg} / \mathrm{m}^{2}\right)$ & $22.1 \pm 0.7$ & $23.2 \pm 1.3$ \\
\hline
\end{tabular}

SD, sleep dysfunction; BMI, body mass index.

Data are expressed as mean \pm SEM or $\mathrm{n}(\%)$.

Table 2. Clinical Characteristics in Subjects With and Without Sleep Dysfunction

\begin{tabular}{lcc}
\hline \multicolumn{1}{c}{ Variable } & $\begin{array}{c}\text { Subjects without } \\
\text { SD }(\mathrm{n}=16)\end{array}$ & $\begin{array}{c}\text { Subjects with } \\
\text { SD }(\mathrm{n}=8)\end{array}$ \\
\hline Threshold volume $(\mathrm{mL})$ & & \\
$\quad$ First sensation & $43.4 \pm 3.6$ & $40.0 \pm 5.0$ \\
Urge & $122.2 \pm 9.4$ & $135.3 \pm 4.5$ \\
Maximal & $184.1 \pm 16.5$ & $195.0 \pm 10.0$ \\
RAIR & $17.5 \pm 0.6$ & $17.5 \pm 0.9$ \\
Anal sphincter pressure (mmHg) & & \\
Resting & $51.6 \pm 4.0$ & $46.0 \pm 5.3$ \\
Maximal & $97.8 \pm 20.9$ & $102.9 \pm 23.6$ \\
Sustained squeeze & $148.6 \pm 20.3$ & $148.1 \pm 25.8$ \\
Length of anal sphincter $(\mathrm{mL})$ & $1.9 \pm 0.2$ & $2.0 \pm 0.3$ \\
Compliance $(\mathrm{mL} / \mathrm{mmHg})$ & $5.9 \pm 0.6$ & $8.0 \pm 1.9$ \\
\hline
\end{tabular}

RAIR, rectoanal inhibitory reflexes; SD, sleep dysfunction.

Data are expressed as mean \pm SEM. sure did not differ between the groups for resting, maximal, or sustained squeeze ( $P=$ NS) (Table 2). The PSQI score in all subjects was $4.9 \pm 1.7$, whereas the STAI-state anxiety score was $46.9 \pm 2.8$. The PSQI score correlated positively with rectal compliance ( $\mathrm{r}=0.66, P=0.007$ ) (Fig. 1). The STAI-state anxiety score was greater in patients with sleep dysfunction than those without sleep dysfunction $(52.4 \pm 2.4$ vs $44.1 \pm 4.0, P=$ 0.02 ). In addition, there were 8 subjects without anxiety and 16 subjects with anxiety. There was no difference between groups regarding any manometric parameters. However, the anxiety score correlated positively with rectal compliance $(\mathrm{r}=0.57, P=$ 0.003) (Fig. 2).

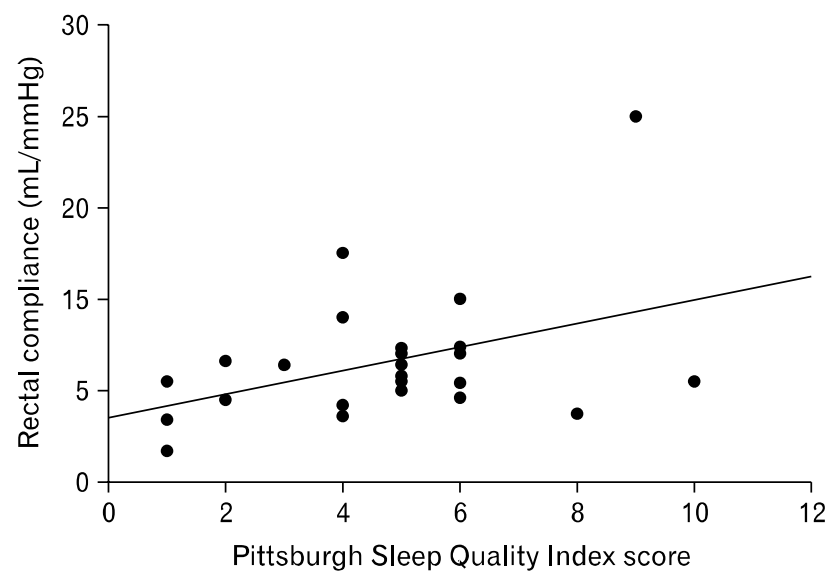

Figure 1. There is a significant positive correlation between sleep quality and rectal compliance $(r=0.66, P=0.007)$.

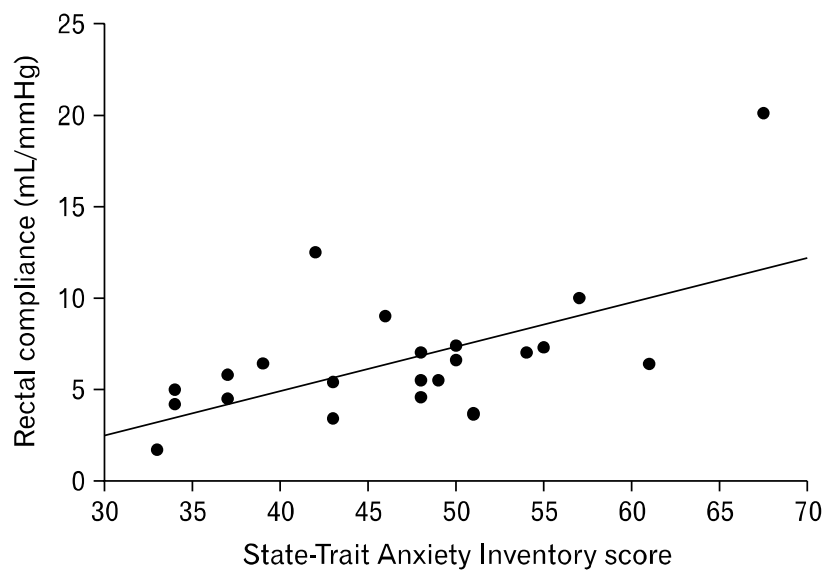

Figure 2. There is a significant positive correlation between anxiety and rectal compliance $(\mathrm{r}=0.57, P=0.003)$. 


\section{Discussion}

In this study, we investigated whether there was any influence of sleep dysfunction on anorectal sensory and motor function, as determined by anorectal manometry in healthy volunteers. We have shown a significantly positive correlation between sleep quality and rectal compliance, although sleep dysfunction did not affect any other parameters of anorectal manometry.

While the influence of sleep disturbance on anorectal function is incompletely understood, recent works have demonstrated close associations of poor sleep with lower GI symptoms. In patients with IBS, it is previously shown that symptom severity of IBS correlates well with the quality of sleep during the prior evening. ${ }^{10}$ Other studies have revealed that poor sleep leads to higher GI symptoms on the following day among women with IBS. $^{11}$

By application of anorectal manometry, we did not observe any difference in anorectal function between patients with and without sleep dysfunction. Earlier studies showed that patients with IBS were characterized by altered objective sleep function as determined by polysomnography. ${ }^{12}$ It is yet unclear whether disturbed sleep function has direct effect on anorectal function, although a previous study reported that abnormal sleep function was linked to the occurrence of disturbed colonic motility. ${ }^{13}$ Moreover, other studies did not disclose any relationship between objective sleep function and IBS symptoms. ${ }^{14}$ The findings of current results being different from previous studies could be by a type II error, since sample size in this study was small. In healthy individuals, colonic motor activity remains quiescent during sleep, and resumes promptly after awakening. ${ }^{15}$ It appears unlikely that sleep itself may directly lead to any deterioration in colonic function or clinical symptoms. Conversely, it may be likely that altered motility may occur during the day after a poor night sleep, ${ }^{3}$ although the effect of sleep deprivation on anorectal motility has not been extensively investigated. Furthermore, functional changes do occur in GI tract during disturbed sleep. $^{12,16}$

Rectal sensation is thought to be conveyed by polymodal unmyelinated $\mathrm{C}$ fibers and thinly myelinated $\mathrm{A} \delta$ fibers ${ }^{17}$ which are polymodal sensory fibers and can encode all types of stimulation. ${ }^{18} \mathrm{~A}$ recent work has shown increased nerve fibers immunoreactive to capsaicin receptor vanilloid receptor 1 (TRPV1) in the mucosal, submucosal and muscle layers of patients with rectal hypersensitivity. ${ }^{19}$ It is suggested that enhanced rectal sen- sitivity together with increased expression of TRPV1 in sensory fibers could be the result of high levels of anxiety. ${ }^{19}$ The relevance of this notion in the mechanism of sleep dysfunction on rectal sensation is yet to be elucidated, although sleep dysfunction might be somewhat associated with anxiety status.

In this study, it appears that there was a predominance of male gender in the group with sleep dysfunction as compared to that without sleep dysfunction. In our previous work, ${ }^{20}$ we had demonstrated in healthy adults that there was no gender difference regarding anorectal parameters. Therefore, it is unlikely that the difference in gender may affect current findings. In addition, current data are similar to those done in our laboratory. ${ }^{20}$

Measurement of rectal compliance is clinically useful regarding the contribution of the rectum to the anorectal problem. ${ }^{21}$ Rectal distension is used in measuring rectal sensation and compliance. ${ }^{22}$ Increased rectal compliance has been demonstrated in physiological conditions such as megarectum and in patients with constipation. ${ }^{23}$ Altered rectal compliance has been demonstrated to correlate with the intensity of rectal sensation. ${ }^{24,25}$ In this study, we demonstrated a significant positive correlation between rectal compliance and the severity of subjective sleep quality as well as anxiety. Our results may indicate that increased sleep dysfunction or anxiety is associated with increased rectal compliance, although sleep dysfunction appears to correlate well with anxiety in our subjects. We also revealed that subjects with sleep dysfunction had higher scores for anxiety than those without sleep dysfunction. It is likely that physical changes underlying anxiety play some role in the presence of sleep dysfunction in healthy subjects.

In a previous work undertaken by Gonlachanvit et $\mathrm{al}^{26}$ who investigated the effects of psychological stressor on rectal sensorimotor function in healthy adults, it was demonstrated that acoustic stress significantly decreased rectal compliance and threshold volumes for the perception of urgency. However, another study has revealed that experimentally induced anxiety did not affect rectal sensitivity or rectal compliance in healthy subjects. ${ }^{27}$ Our results are apparently different from the findings by applying acoustic stress. The discrepancy is not clear, although it can be attributed to different methods and designs of the experiment. An earlier study interestingly indicated that using sleep deprivation as a chronic stressor increased rectal sensitivity. ${ }^{5}$ Although we did not perform any experiment of sleep deprivation in this study, our data suggest a potential role of sleep-related alteration in anorectal function in a group of healthy subjects reporting poor sleep. Further experiment is necessary to investigate whether direct 
sleep deprivation would alter anorectal physiology.

In summary, we have shown that sleep dysfunction did not influence the majority of anorectal parameters in healthy adults, although increased rectal compliance was associated with sleep dysfunction as well as anxiety. The results might implicate a complex interrelationship between these psychological factors and anorectal function. Future work on the role of sleep related alteration in anorectal motility will undoubtedly help elucidating the role of brain-gut axis as well as symptom perturbation in patients with functional bowel disorders.

\section{References}

1. Chang $\mathrm{L}$. The association of functional gastrointestinal disorders and fibromyalgia. Eur J Surg Suppl 1998;583:32-36.

2. Fass R, Fullerton $S$, Tung $S$, Mayer EA. Sleep disturbances in clinic patients with functional bowel disorders. Am J Gastroenterol 2000;95:1195-2000.

3. Orr WC, Chen CL. Sleep and the gastrointestinal tract. Neurol Clin 2005;23:1007-1024.

4. Orkin BA, Soper NJ, Kelly KA, Dent J. Influence of sleep on anal sphincteric pressure in health and after ileal pouch-anal anastomosis. Dis Colon Rectum 1992;35:137-144.

5. Houghton LA, Prior A, Whorwell PJ. Effect of acute stress on anorectal physiology in normal healthy volunteers. Eur J Gastroenterol Hepatol 1994;6:389-392.

6. Longstreth GF, Thompson WG, Chey WD, Houghton LA, Mearin F, Spiller RC. Functional bowel disorders. Gastroenterology 2006;130:1480-1491.

7. Buysse DJ, Reynolds CF 3rd, Monk TH, Berman SR, Kupfer DJ. The pittsburgh sleep quality index: a new instrument for psychiatric practice and research. Psychiatry Res 1989;28:193-213.

8. Spielberger CD, Gorsuch RL, Lushene RE. Manual for the state-trait anxiety inventory. Palo Alto, CA: Consulting Psychologists Press 1970:80-82.

9. Spielberger CD. State-trait anxiety inventory. Mountain view, CA: Consulting Psychologists Press 1983:1-307.

10. Goldsmith G, Levin JS. Effect of sleep quality on symptoms of irritable bowel syndrome. Dig Dis Sci 1993;38:1809-1814.

11. Jarrett M, Heitkemper M, Cain KC, Burr RL, Hertig V. Sleep disturbance influences gastrointestinal symptoms in women with irritable bowel syndrome. Dig Dis Sci 2000;45:952-959.

12. Orr WC, Crowell MD, Lin B, Harnish MJ, Chen JD. Sleep and gastric function in irritable bowel syndrome: derailing the brain-gut axis. Gut 1997;41:390-393.

13. Furukawa Y, Cook IJ, Panagopoulos V, McEvoy RD, Sharp DJ, Simula M. Relationship between sleep patterns and human colonic motor patterns. Gastroenterology 1994;107:1372-1381.

14. Elsenbruch S, Harnish MJ, Orr WC. Subjective and objective sleep quality in irritable bowel syndrome. Am J Gastroenterol 1999; 94:2447-2452.

15. Narducci F, Bassotti G, Gaburri M, Morelli A. Twenty four hour manometric recording of colonic motor activity in healthy man. Gut 1987;28:17-25.

16. Kellow JE, Gill RC, Wingate DL. Prolonged ambulant recordings of small bowel motility demonstrate abnormalities in the irritable bowel syndrome. Gastroenterology 1990;98(5 Pt 1):1208-1218.

17. Duthie HL, Gairns FW. Sensory nerve-endings and sensation in the anal region of man. Br J Surg 1960;47:585-595.

18. Su X, Gebhart GF. Mechanosensitive pelvic nerve afferent fibers innervating the colon of the rat are polymodal in character. J Neurophysiol 1998;80:2632-2644.

19. Chan CL, Facer P, Davis JB, et al. Sensory fibres expressing capsaicin receptor TRPV1 in patients with rectal hypersensitivity and faecal urgency. Lancet 2003;361:385-391.

20. Liu TT, Chen CL, Yi CH, Tung PC, Chen CH. Gender difference in anorectal function in healthy young Taiwanese. Gastroenterol J Taiwan 2008;25:171-175.

21. Felt-Bersma RJ, Sloots CE, Poen AC, Cuesta MA, Meuwissen SG. Rectal compliance as a routine measurement: extreme volumes have direct clinical impact and normal volumes exclude rectum as a problem. Dis Colon Rectum 2000;43:1732-1738.

22. Read NW, Haynes WG, Bartolo DC, et al. Use of anorectal manometry during rectal infusion of saline to investigate sphincter function in incontinent patients. Gastroenterology 1983;85:105-113.

23. Waldron D, Bowes KL, Kingma YJ, Cote KR. Colonic and anorectal motility in young women with severe idiopathic constipation. Gastroenterology 1988;95:1388-1394.

24. Salvioli B, Bharucha AE, Rath-Harvey D, Pemberton JH, Phillips SF. Rectal compliance, capacity, and rectoanal sensation in fecal incontinence. Am J Gastroenterol 2001;96:2158-2168.

25. Siproudhis L, Bellissant E, Juguet F, Allain H, Bretagne JF, Gosselin M. Perception of and adaptation to rectal isobaric distension in patients with faecal incontinence. Gut 1999;44:687-692.

26. Gonlachanvit S, Rhee J, Sun WM, Chey WD. Effect of acute acoustic stress on anorectal function sensation in healthy human. Neurogastroenterol Motil 2005;17:222-228.

27. Geeraerts B, van Oudenhove L, Vos R, Tack J. Influence of experimentally induced anxiety on rectal sensorimotor function in healthy humans. Neurogastroenterol Motil 2008;20:1227-1233. 